\title{
UNRESOLVED ISSUES
}

\section{The ethics of a clinical trial when the protocol clashes with international guidelines}

\author{
N. T. N. Lan, ${ }^{1}$ N. T. N. Thu, ${ }^{2}$ N. H. Duc, ${ }^{1}$ N. N. Lan, ${ }^{1}$ T. T. X. Lien, ${ }^{2}$ N. H. Dung, ${ }^{1}$ A-M. Taburet, ${ }^{3}$ \\ D. Laureillard, ${ }^{4}$ L. Borand, ${ }^{5}$ C. Quillet, ${ }^{4}$ D. Lagarde, ${ }^{6}$ A. Pym, ${ }^{7}$ C. Connolly, ${ }^{8}$ C. Lienhardt, ${ }^{9}$ \\ C. Rekacewicz, ${ }^{10}$ A. D. Harries 6,11
}

http://dx.doi.org/10.5588/pha.13.0017

Due to their nature and complexity, clinical trials often take some time to launch after the protocol has been designed and ethics approval obtained. During this time, there may be changes in international treatment guidelines and recommendations that result in a conflict between study protocol and recommended international best practice. Here, we describe the situation that arose in a pharmacokinetic study on the use of two different doses of rifabutin in patients with human immunodeficiency virus-associated tuberculosis who initiated antiretroviral therapy (ART) with a lopinavir-ritonavir-based regimen in South Africa and Viet Nam. The study protocol specified that ART should be started 10 weeks after the start of anti-tuberculosis treatment. The study in South Africa was approved in June 2008, went ahead as scheduled and was completed in August 2010. The study in Viet Nam was approved in October 2008 and was started in June 2010. A few weeks later, the World Health Organization released their 2010 guidelines for adult ART; one of its strong recommendations (with moderate quality of evidence) was that ART should be started 2-8 weeks after the start of anti-tuberculosis treatment. Emerging scientific evidence also supported this recommendation. The investigators felt that the Viet Nam study protocol was in conflict with recommended international best practice, and the trial was stopped in October 2010. An amended study protocol in which ART was started at 2 weeks was developed and implemented. The ethics issues around this decision and the need to change the study protocol are discussed in this article.

$\mathrm{D}$ espite sound, up-to-date international policy and treatment guidelines, ${ }^{1,2}$ human immunodeficiency virus (HIV) associated tuberculosis (TB) remains a major global public health problem: in 2011, there were an estimated 1.1 million persons with HIVassociated TB, of whom 430000 died. ${ }^{3}$ Antiretroviral therapy (ART) is the most important HIV-related intervention, reducing mortality, improving immunological and virological responses and reducing the risk of recurrent TB disease. ${ }^{4}$ The most recent World Health Organization (WHO) ART guidelines recommend that all patients with HIV-associated TB are eligible for ART, regardless of CD4 count. ${ }^{5}$ Major challenges arise when patients need to receive both second-line ART and anti-tuberculosis treatment.
In most low- and middle-income countries, protease inhibitors (PIs), combined with low-dose ritonavir to enhance pharmacokinetics, form the backbone of second-line ART regimens, with lopinavir/ritonavir $(\mathrm{LPV} / \mathrm{r})$ being the most common formulation used. Unfortunately, rifampicin (RMP) significantly reduces the plasma concentrations of all known PIs by $75-95 \%$ by induction of cytochrome 3A4 (CYP3A4) enzymes. ${ }^{6}$ Attempts to overcome this adverse drug-drug interaction by either increasing the PI dose or altering the dose of RMP have been thwarted by hepatotoxicity, 7 and such approaches are in any case incompatible with large-scale and decentralised public sector rollout of ART.

Rifabutin (RBT) is an attractive alternative rifamycin to RMP, as it is a less potent inducer of CYP3A4, ${ }^{8}$ and the drug can be combined with most unboosted and boosted PIs without PI dose adjustment. RBT is recommended at a standard dose of $300 \mathrm{mg}$ daily for the prophylaxis and treatment of Mycobacterium avium complex and the treatment of drug-susceptible TB. Plasma concentrations of RBT are increased in the presence of $\mathrm{PIs}^{6}{ }^{6}$ dose adjustments are therefore recommended when RBT is combined with a PI. The 1998 guidelines of the US Centers for Disease Control and Prevention recommended that the dose of RBT be reduced from $300 \mathrm{mg}$ to $150 \mathrm{mg}$ in the presence of a PI, ${ }^{9}$ and in 2004 that a dose of $150 \mathrm{mg}$ two or three times a week should be used in combination with LPV/r. ${ }^{10}$ However, recent reports have shown that intermittent dosing is suboptimal and can result in inadequate rifamycin levels that, in turn, can lead to TB relapse and acquired rifamycin resistance. ${ }^{11-14}$

A protocol was therefore written with the primary aim of comparing the plasma concentrations of two different doses of RBT (150 mg three times per week and $150 \mathrm{mg}$ daily) in patients with HIV-associated TB who initiated ART with LPV/r in South Africa and Viet Nam. Because of the interest in the use of RBT with non-nucleoside reverse transcriptase inhibitors (NNRTIs), the study protocol also included the study of different doses of RBT (600 mg, $450 \mathrm{mg}$ and $300 \mathrm{mg}$ ) in combination with efavirenz (EFV) or nevirapine. The study protocol in South Africa (Agence nationale de recherches sur le sida [ANRS] 12150a, clinical trial registry number NCT00640887) was finalised in August 2007 and approved in June 2008. The study protocol in Viet Nam (ANRS 12150b, clinical trial registry

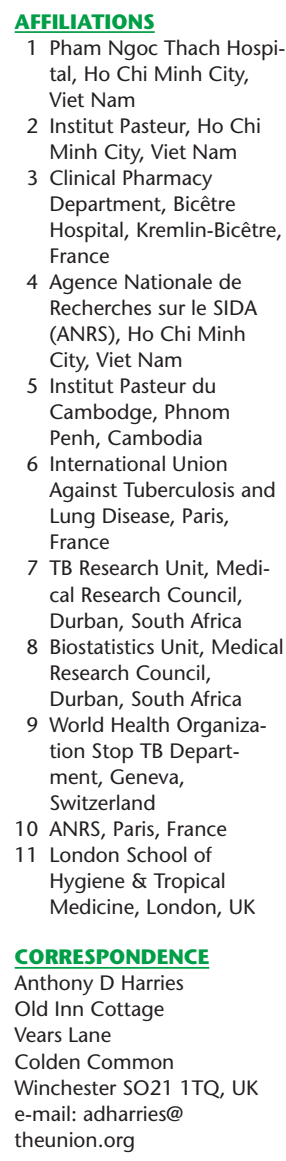

7 TB Research Unit, Medical Research Council, Durban, South Africa

8 Biostatistics Unit, Medical Research Council, Durban, South Africa

9 World Health Organiza tion Stop TB Department, Geneva, Switzerland

10 ANRS, Paris, France

11 London School of Hygiene \& Tropical Medicine, London, UK

CORRESPONDENCE Anthony D Harries Old Inn Cottage Vears Lane

Colden Common Winchester SO21 1TQ, UK e-mail: adharries@ theunion.org

\section{KEY WORDS}

tuberculosis; antiretroviral therapy; HIV; pharmacokinetic trials; ethics

Received 18 March 2013 Accepted 21 May 2013

PHA 2013; 3(2): 97-102 (C) 2013 The Union 
number NCT00651066) was finalised in March 2008 and approved in October 2008.

\section{INITIAL PROTOCOL DESIGN}

An open-label, three-period, cross-over drug interaction study was planned to investigate the pharmacokinetics of RBT with and without PI-based ART in African and Vietnamese TB patients co-infected with HIV. The detailed trial timeline describing the allocation of PI and NNRTI treatments in the three arms of the trial in relation to the initial and continuation phases of antituberculosis treatment and randomisation is shown in Figure 1. In this protocol, the initiation of ART was at 10 weeks after the start of TB treatment, during the continuation phase with RBT and isoniazid (INH).

Study patients were adults aged 18-65 years, HIVpositive, with a CD 4 count of $\leqslant 250$ cells/ $\mu$ l in South Africa and 50-200 cells/ $\mu$ l in Viet Nam, and with newly diagnosed TB. Similar inclusion and exclusion criteria pertained to the African and Vietnamese patients, including provision of written informed consent, a diagnosis of pulmonary TB confirmed by smear microscopy or culture, a Karnofsky score of $\geqslant 80$, no previous TB episode within the last 12 months, no history of prior treatment for multidrug-resistant $\mathrm{TB}$, no concomitant opportunistic infections, no formal contraindication to any trial medication, no diabetes mellitus, no recreational drug or alcohol abuse and normal haematological and biochemical parameters.

The pharmacokinetic (PK) evaluations were carried out at 10, 14 and 18 weeks (Figure 1). This involved admitting the patient to hospital the night before, drawing a blood sample prior to the administration of study drugs and then drawing further blood samples eight times in the first $24 \mathrm{~h}$ and once more at $48 \mathrm{~h}$. RBT and 25-O-desacetylrifabutin were analysed with a validated high performance liquid chromatography assay.

\section{THE PROBLEM}

The study started in South Africa in February 2009, and the clinical trial was completed by August 2010. When the study started, the WHO ART guidelines (2006 revised version) in force at the time acknowledged that the optimum time to start ART in relation to anti-tuberculosis treatment in HIV-infected TB patients was not known. While awaiting the results of current research studies, the WHO provisionally recommended that in patients with CD4 cell counts of $<200$ cells/ $\mu$ l, ART should be started between 2 and 8 weeks and in those patients in whom CD4 cell counts were between 200 and 350 cells/ $\mu$ l, ART could be delayed until after the initial phase of anti-tuberculosis treatment had been completed. ${ }^{15}$ Given the uncertainty about the optimal time to start ART, the provisional nature of the recommendations and the simplification of management if patients started ART in the continuation phase of TB treatment when only two TB medications were taken, it was felt that the study protocol, which specified that ART should be started
ACKNOWLEDGEMENTS The authors thank the patients for their participation in the study. They acknowledge and thank the French National Institute for Health and Medical Research-French National Agency for Research on AIDS and Viral Hepatitis (INSERM-ANRS) for providing sponsorship and funding for the study, Fondation Total for their grant, Laboratoires SERB and Merck Sharp \& Dohme Ltd for their generous donation of medicines and Pfizer (South Africa) for the donation of RBT and 25-O-desacetyl RBT reference powder.

$\mathrm{CL}$ is a staff member of the World Health Organization (WHO); the author alone is responsible for the views expressed in this publication and these do not necessarily represent the decisions, policy or views of the WHO. Conflict of interest: none declared.

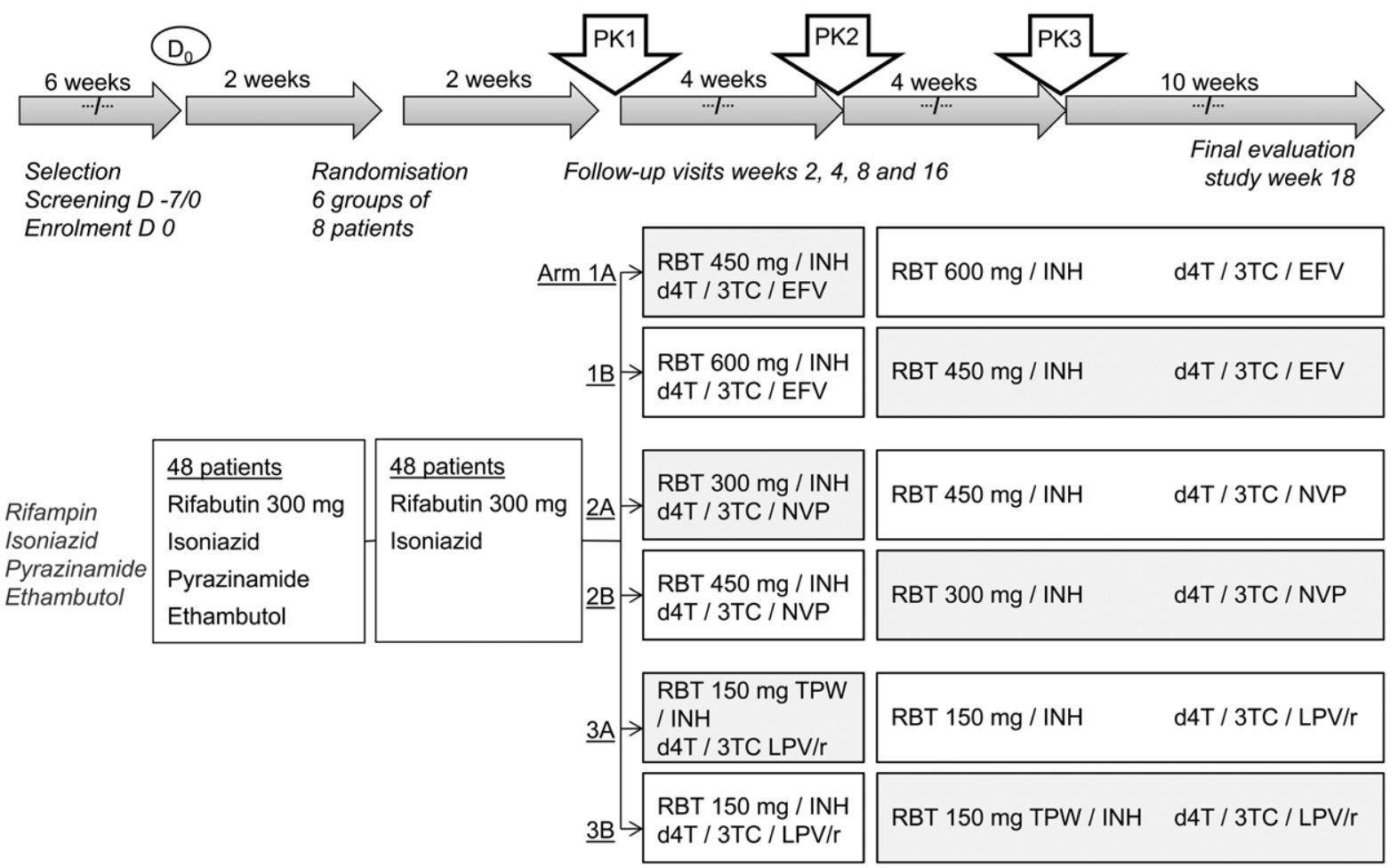

FIGURE 1 Timeline and randomisation of the first PK trial of RBT with antiretroviral treatment in HIV-infected patients with TB designed for South Africa and Viet Nam. PK = pharmacokinetic; RBT = rifabutin; INH = isoniazid; d4T = stavudine; $3 \mathrm{TC}=$ lamivudine; $\mathrm{EFV}=$ efavirenz; NVP = nevirapine; TPW = three times per week; LPV/r = lopinavir/ ritonavir; HIV = human immunodeficiency virus. 
TABLE WHO recommendations in 2010 for HIV-TB coinfection ${ }^{5}$

1 Start ART in all HIV-infected individuals with active TB, irrespective of the CD4 cell count (strong recommendation, low quality of evidence)

2 Start anti-tuberculosis treatment first, followed by ART as soon as possible afterwards (and within the first 8 weeks; strong recommendation, moderate quality of evidence)

3 Use efavirenz as the preferred NNRTI in patients starting ART while on anti-tuberculosis treatment (strong recommendation, high quality of evidence)

$\mathrm{WHO}=$ World Health Organization; HIV $=$ human immunodeficiency virus; $\mathrm{TB}=$ tuberculosis; ART = antiretroviral therapy; NNRTI = non-nucleoside reverse transcriptase inhibitor.

10 weeks after initiation of anti-tuberculosis treatment, was not in conflict with WHO guidelines.

For various reasons, study implementation was delayed in Viet Nam, and the first patient was recruited into the study in June 2010. However, in mid-2010, the WHO released its new ART guidelines, with a strong recommendation that in all HIV-infected persons with TB ART should be initiated as soon as possible after the start of anti-tuberculosis treatment and in any case within the first 8 weeks (Table). ${ }^{5}$ Furthermore, an on-going trial from Cambodia (CAMbodian Early vs. Late Introduction of Antiretroviral therapy [CAMELIA]) supported starting ART much earlier, within 2 weeks of anti-tuberculosis treatment; these findings were being presented at international conferences at the time, eventually resulting in publication in the medical literature in October 2011. ${ }^{16}$ The trial team became concerned that delaying ART until the tenth week of anti-tuberculosis treatment as per study protocol was therefore not in agreement with the new WHO recommendations $s^{5}$ or emerging new scientific evidence, although the randomised controlled studies were not formally published in their entirety until October 2011,16-18 after the decision to change the protocol had already been made. Based mainly on the new WHO
2010 ART guidelines, in October 2010, after 74 patients had been pre-screened and eight patients enrolled in the study, a unanimous decision was taken by all study implementers and the study sponsor (ANRS, France) to stop recruiting patients to the trial. Patients already in the study were referred back to their national programmes for care and treatment, and it was agreed that the study protocol be amended to be in line with new international recommendations.

\section{THE AMENDED NEW PROTOCOL}

The protocol was changed with the aim of studying the interaction between RBT and PIs that was in agreement with current WHO guidelines, and this was resubmitted for ethics approval to the national government and the International Union Against Tuberculosis and Lung Disease. The focus was exclusively on the interaction between RBT and LPV/r, with no assessment of NNRTIs as in the initial protocol. The trial timeline, randomisation groups and process are shown in Figure 2. Briefly, at enrolment into the trial, patients were started on RBT $300 \mathrm{mg}$ once a day (OD), in combination with standard doses of INH, pyrazinamide (PZA) and ethambutol (EMB). After 2 weeks (representing the first 2 weeks of the initial phase of treatment), the first pharmacokinetic study (PK1) was performed. Patients were then started on ART with stavudine or zidovudine-lamivudine-LPV/r (d4T/3TC/LPV/r, taken twice daily) as recommended by the WHO and Vietnamese HIV/ AIDS (acquired immune-deficiency syndrome) guidelines. The second and third PK studies were conducted at 5 and 8 weeks respectively, with the same blood draw schedule and analysis methodology that were used in the initial protocol.

After the last PK study, patients stopped RBT, INH, PZA and $\mathrm{EMB}$, and started the continuation phase of anti-tuberculosis treatment with RH under the care of the National TB Programme. $\mathrm{LPV} / \mathrm{r}$ was stopped and changed to EFV, in line with National

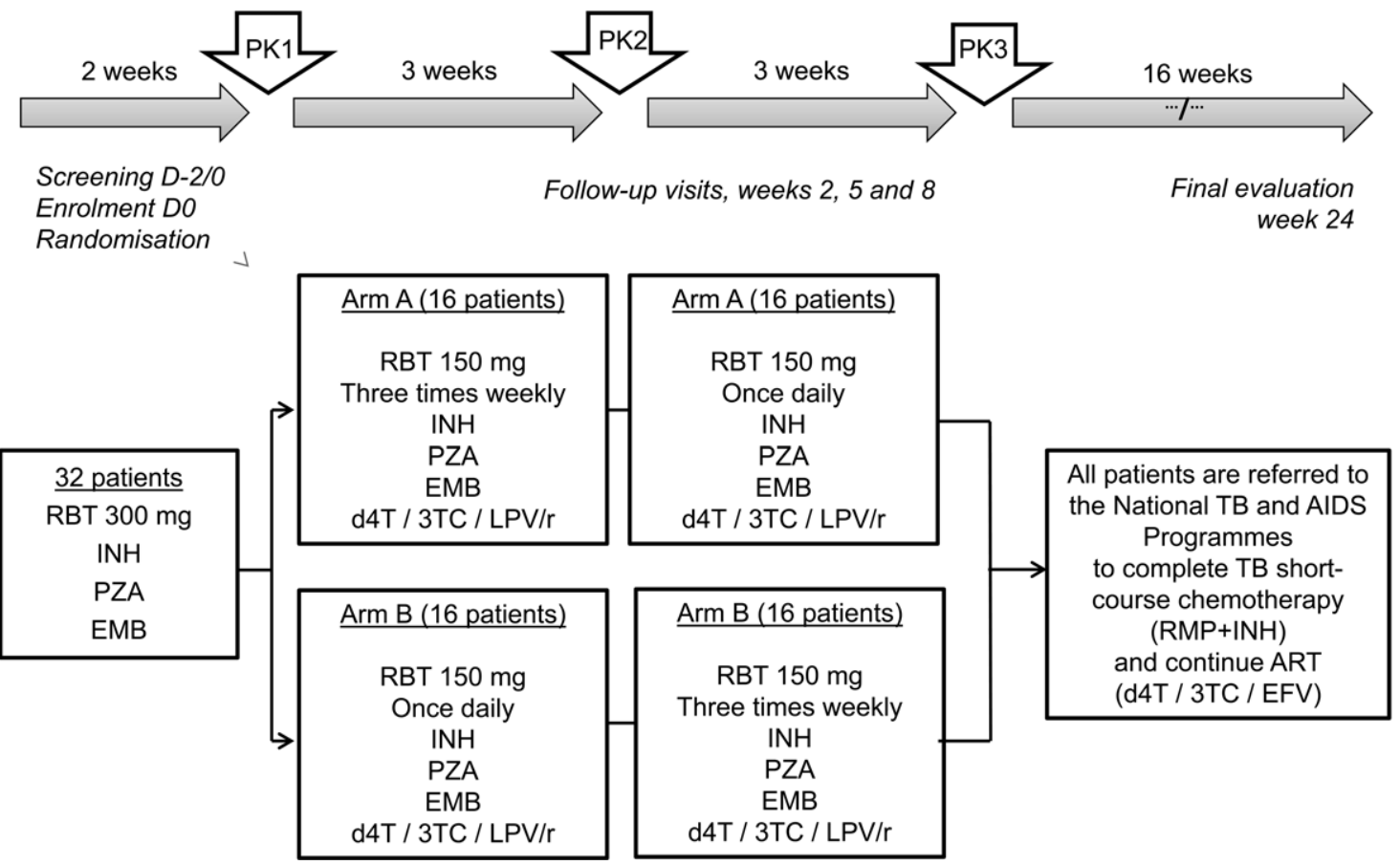

FIGURE 2 Timeline and randomisation of the second PK trial of RBT with antiretroviral treatment in HIV-infected patients with TB designed for Viet Nam. PK = pharmacokinetic; RBT = rifabutin; INH = isoniazid; PZA = pyrazinamide; EMB = ethambutol; d4T = stavudine; $3 T C=$ lamivudine; $\mathrm{LPV} / \mathrm{r}=$ lopinavir/ritonavir; $\mathrm{TB}=$ tuberculosis; AIDS = acquired immune-deficiency syndrome; ART = antiretroviral therapy. 
AIDS Programme guidelines. Patients were followed up to the end of anti-tuberculosis treatment for another 16 weeks and then further followed up within the National AIDS Programme.

Patient recruitment was re-opened in September 2011 and was completed in March 2012. The trial was completed by September 2012. Data analysis is currently in progress.

\section{DISCUSSION}

To stop a clinical trial several years after getting it off the ground while patient recruitment is on-going and money has been spent is not an easy decision. The decision on ethical grounds, though, was clear: it did not seem correct to delay ART until the tenth week of anti-tuberculosis treatment when new WHO guidelines made a strong recommendation, based on moderate quality of evidence, for the earlier start of ART in the first 8 weeks to reduce mortality. ${ }^{5}$ Supportive scientific evidence was also emerging at the time, mainly from presentations made at international conferences of the CAMELIA trial, although the results of the CAMELIA, STRIDE (Start of Anti-HIV Therapy in HIV-Infected Adults Being Treated for Tuberculosis) and SAPiT (Starting ARV therapy at three points in TB therapy) trials were only published 1 year after the decision to stop the Viet Nam study had been made.

In Cambodia, the published results of the CAMELIA trial showed that in HIV-infected patients with CD4 counts of $<200$ cells $/ \mu l$, those who started ART 2 weeks after anti-tuberculosis treatment had a significantly reduced mortality compared with those starting at 8 weeks, with a more pronounced benefit in those with CD 4 counts of $<50$ cells/ $\mu 1 .{ }^{16}$ The other two trials, which were multi-country (STRIDE) and from South Africa (SAPiT), however, showed that earlier ART was associated with a lower rate of AIDSdefining illness and death only in those patients whose CD4 counts were $<50$ cells/ $\mu 1 .{ }^{17,18}$ For those with less advanced immune suppression, there was no benefit. In fact, in all those starting ART early there was a trend towards increased side effects from immune reconstitution inflammatory syndrome (IRIS) and an increased frequency of changing regimens due to adverse effects. Nevertheless, if we had been given the results of these trials at the time that we discussed stopping the Viet Nam study, it is likely that we would still have made the same decision to stop. The CAMELIA trial in Cambodia was more in line with the Viet Nam PK study. The other two trials were different-the multicountry STRIDE trial recruited patients with both confirmed and suspected TB, and the South African SAPiT trial recruited patients with smear-positive TB and CD 4 counts of $<500$ cells/ $\mu$ l. Furthermore, in the CAMELIA trial the primary end point was survival while in the other two trials the primary end point was a composite of survival and AIDS-defining illness.

This is not the first time that such a dilemma has occurred in clinical trials that have investigated the optimal time to start ART in HIV-infected TB patients. The first SAPiT trial, an openlabel, randomised, controlled trial in South Africa that began in June 2005, was designed to evaluate the best time to start ART either during anti-tuberculosis treatment (in two integrated-therapy groups) or after the completion of anti-tuberculosis treatment (in one sequential-therapy group). The sequential-therapy group was stopped in September 2008 by the data and safety monitoring committee after an interim analysis showed that there was a relative reduction of $56 \%$ (hazard ratio in the combined integratedtherapy groups $0.44 ; 95 \%$ confidence interval $0.25-0.79 ; P=0.003$ ) if patients started ART during anti-tuberculosis treatment rather than waiting until TB treatment was completed. ${ }^{19}$
The clinical trial was attacked by bioethicists arguing that it was unethical and substandard clinical practice to randomise immune-suppressed patients to defer ART until anti-tuberculosis treatment was completed, arguing that it caused harm and preventable deaths for a substantial number of impoverished and poorly educated South African trial participants. ${ }^{20}$ This was also taken up by a group of mainly South African researchers who argued that the trial design was appropriate for patients with CD4 cell counts in the range of 200-500 cells/ $\mu \mathrm{l}$, but inappropriate for patients with advanced disease and CD 4 cell counts of $<200$ cells/ $\mu 1 .{ }^{21}$ The group cited studies (all observational) showing that HIV-infected patients with CD4 counts of $<200$ cells/ $\mu$ l had high mortality during anti-tuberculosis treatment, that the occurrence of side effects associated with IRIS was associated with a low mortality risk, that effective ART regimens were available that could be taken with anti-tuberculosis treatment and that ART reduced mortality when commenced during anti-tuberculosis treatment. The group felt that equipoise in terms of when to start ART was not met for those patients with low CD4 counts, and thus randomisation of this subset of patients should not have occurred.

In their defence, the first SAPiT investigators maintained that at the time that the trial started, clinical care for HIV-infected TB patients was based on the WHO 2003 ART guidelines, ${ }^{22}$ which stated that the optimal time to start ART was not known, that there was in fact clinical equipoise around the issue of whether to start all HIV-infected patients during or after anti-tuberculosis treatment and that all the cited studies were observational and therefore subject to the usual problems of confounding and bias.

Ethics principles for medical research in human subjects in the World Medical Association's Declaration of Helsinki state that 'the best current intervention should be provided as the standard of care to patients in studies'. ${ }^{23}$ In its ethics charter for research in developing countries, ${ }^{24}$ the ANRS, the sponsor of this trial, clearly states that for patients participating in research studies, protection should be the priority. Research participants during a study should be no worse off than they would be if they did not participate in a study, and any study offering less than the current standard of care should be reviewed by the trial steering group and the trial investigators themselves. In the Vietnamese PK study, due to the length of time between study approval and implementation, international guidelines, supported by emerging scientific evidence, changed the playing field, rendering the study protocol standard of care suboptimal. It was unethical to continue, and regardless of time, energy and costs, the trial in our opinion had to be stopped.

At this stage we had two options-to stop and abandon any further PK study in its entirety, or to redesign a new protocol. We decided on the latter as we still had funds, although half the amount we had had when we started, and information on RBT drug doses was needed from a setting outside of South Africa. We realised that our original aim of directly comparing findings between Vietnamese and African patients could not be realised as the two protocols were different, and we could only focus on the most important of the drug interactions, namely RBT and LPV/r. Despite these challenges, we can still learn from the pharmacokinetics findings in Viet Nam, which will serve for adapting treatment for HIV-infected patients with TB in both Africa and Asia.

In conclusion, a study protocol to assess the PK characteristics of RBT in patients with HIV-associated TB who initiated ART with a LPV/r based regimen in Viet Nam conflicted with updated WHO ART guidelines and emerging scientific evidence. The study was 
stopped and an amended study protocol was developed. Although this resulted in having to start the study again from the start and will mean that there cannot be direct comparisons between Viet Nam and South Africa, this was the correct decision, as patients' interests and international best practices were put first. We hope that this description and discussion of this process will help other researchers if they are faced with similar dilemmas in the future.

\section{References}

1 World Health Organization. WHO policy on collaborative TB/HIV activities. Guidelines for national programmes and other stakeholders. WHO/HTM/ TB/2012.1. WHO, Geneva, Switzerland.

2 World Health Organization. Treatment of tuberculosis. Guidelines. 4th ed. WHO/HTM/TB/2009.420. WHO, Geneva, Switzerland.

3 World Health Organization. Global tuberculosis report, 2012. WHO/HTM/ TB/2012.6. WHO, Geneva Switzerland.

4 Harries A D, Zachariah R, Corbett E L, et al. The HIV-associated tuberculosis epidemic-when will we act? Lancet 2010; 375: 1906-1919.

5 World Health Organization. Antiretroviral therapy for HIV infection in adults and adolescents. Recommendations for a public health approach. 2010 revision. Geneva, Switzerland: WHO, 2010.

6 Loeliger A, Suthar A B, Ripin D, et al. Protease inhibitor-containing antiretroviral treatment and tuberculosis: can rifabutin fill the breach? Int J Tuberc Lung Dis 2012; 16: 6-15.

7 Burman W, Gallicano K, Peloquin C. Comparative pharmacokinetics and pharmacodynamics of the rifamycin antibacterials. Clin Pharmacokinet 2001; 40: 327-341.

8 Baciewicz A M, Chrisman C R, Funch C K, Self T H. Update on rifampin and rifabutin drug interactions. Am J Med Sci 2008; 335: 126-136.

9 Centers for Disease Control and Prevention. Prevention and treatment of tuberculosis among patients infected with human immunodeficiency virus: principles of therapy and revised recommendations. MMWR 1998; 47(RR-20): $1-51$.

10 Centers for Disease Control and Prevention. Updated guidelines for the use of rifamycins for the treatment of tuberculosis among HIV-infected patients taking protease inhibitors or non-nucleoside reverse transcriptase inhibitors. MMWR 2004; 53(RR-15): 1-112.

11 Boulanger C, Hollander E, Farrell K, et al. Pharmacokinetic evaluation of ri- fabutin in combination with lopinavir-ritonavir in patients with HIV infection and active tuberculosis. Clin Infect Dis 2009; 49: 1305-1311.

12 Khachi H, O'Connell R, Ladenheim D, Orkin C. Pharmacokinetic interactions between rifabutin and lopinavir/ritonavir in HIV-infected patients with mycobacterial co-infection. J Antimicrob Chem 2009; 64: 871-873.

13 Jenny-Avital E, Joseph K. Rifamycin-resistant Mycobacterium tuberculosis in the highly active antiretroviral therapy era: a report of 3 relapses with acquired rifampin resistance following alternate-day rifabutin and boosted protease inhibitor therapy. Clin Infect Dis 2009; 48: 1471-1474.

14 Weiner M, Benator D, Burman W, et al. Association between acquired rifamycin resistance and the pharmacokinetics of rifabutin and isoniazid among patients with HIV and tuberculosis. Clin Infect Dis 2005; 40: 1481-1491.

15 World Health Organization HIV/AIDS Programme. Antiretroviral therapy for HIV infection in adults and adolescents: recommendations for a public health approach. 2006 revision. Geneva, Switzerland: WHO, 2006.

16 Blanc F X, Sok T, Laureillard D, et al. Earlier versus later start of antiretrovira therapy in HIV-infected adults with tuberculosis. N Engl J Med 2011; 365 1471-1481.

17 Havlir D V, Kendall M A, Ive P, et al. Timing of antiretroviral therapy for HIV-1 infection and tuberculosis. N Engl J Med 2011; 365: 1482-1491.

18 Karim S S A, Naidoo K, Grobler A, et al. Integration of antiretroviral therapy with tuberculosis treatment. N Engl J Med 2011; 365: 1492-1501.

19 Karim S S A, Naidoo K, Grobler A, et al. Timing of initiation of antiretroviral drugs during tuberculosis therapy. N Engl J Med 2010; 362: 697-706.

20 Cohen J. Bioethicists assail a celebrated TB/HIV treatment trial. Science 2010; 328: 799-801.

21 Boulle A, Clayden P, Cohen K, et al. Prolonged deferral of antiretroviral therapy in the SAPiT trial: did we need a clinical trial to tell us that this would increase mortality? S Afr Med J 2010; 100: 566-571.

22 World Health Organization. Scaling up antiretroviral therapy in resourcelimited settings: treatment guidelines for a public health approach. $2003 \mathrm{Re}-$ vision. Geneva, Switzerland: WHO, 2004.

23 World Medical Association. Declaration of Helsinki. Ethical principles for medical research involving human subjects. Ferney-Voltaire, France: WMA, 2008. http://www.wma.net/en/30publications/10policies/b3/index.html Accessed May 2013

24 Agence française de Recherches sur le VIH/SIDA et les Hépatites virales. Ethics charter for research in developing countries. Paris, France: ANRS, 2008 http://www.anrs.fr/layout/set/print/Ressources-et-publications/Publications/ Publications-ANRS/Ethics-charter-for-research-in-developing-countries Accessed May 2013.
Du fait de la nature et de la complexité des études cliniques, leur mise en œuvre est souvent longue après l'élaboration du protocole et son approbation éthique. Pendant cette période, il peut y avoir un changement des lignes directrices internationales de traitement et des recommandations qui provoquent un conflit entre le protocole et les meilleures pratiques recommandées internationalement. Nous décrivons ici la situation apparue dans une étude pharmacocinétique portant sur l'utilisation de deux doses différentes de rifabutin chez des patients atteints de tuberculose (TB) associée au virus de l'immunodéficience humaine et commençant un traitement antirétroviral (ART) à base de lopinavir-ritonavir en Afrique du Sud et au Viet Nam. Le protocole de l'étude spécifiait de commencer I'ART 10 semaines après le début de la thérapie antituberculeuse. En Afrique du Sud, I'étude a été approuvée en juin 2008, s'est déroulée comme prévu et a été achevée en juin 2010. Au Viet Nam, l'étude a été approuvée en octobre 2008 et a démarré en juin 2010. Quelques semaines après, l'Organisation Mondiale de la Santé a publié ses lignes directrices de 2010 pour l'utilisation de l'ART chez les adultes, dont l'une des vives recommandations (basée sur des données de qualité modérée) était de commencer I'ART entre 2 et 8 semaines après le début du traitement de la TB. L'arrivée de nouvelles preuves scientifiques est aussi venue à l'appui de cette recommandation. Les investigateurs ont eu le sentiment que le protocole d'étude au Viet Nam était en conflit avec les meilleures pratiques internationales et l'étude a été arrêtée en octobre 2010. Un protocole d'étude amendé a été développé et mis en œuvre. Les problèmes éthiques entourant cette décision et la nécessité de changer le protocole sont discutés dans ce papier.
Los ensayos clínicos, dadas sus características y su complejidad, suelen exigir mucho tiempo desde la elaboración del protocolo y la aprobación por parte del comité de ética hasta su realización. Durante este lapso, pueden surgir modificaciones en las recomendaciones y las directrices terapéuticas internacionales, lo cual genera un conflicto entre el protocolo del estudio y las prácticas óptimas recomendadas. A continuación se describe la situación que se presentó en Suráfrica y Viet Nam durante un estudio de farmacocinética sobre el uso de dos dosificaciones diferentes de rifabutina, en pacientes aquejados de tuberculosis (TB) asociada con la infección por el virus de la inmunodeficiencia humana (HIV), quienes habían comenzado el tratamiento antirretrovírico (ART) con un régimen basado en la asociación lopina- vir y ritonavir. El protocolo del estudio precisaba que el ART se debía comenzar 10 semanas después de haber iniciado el tratamiento antituberculoso. En Suráfrica, el estudio recibió la aprobación en junio del 2008, comenzó en el tiempo previsto y se completó en agosto del 2010. En Viet Nam, se obtuvo la aprobación del estudio en octubre del 2008 y se comenzó en junio del 2010. A las pocas semanas, la Organización Mundial de Salud publicó sus directrices del ART en los adultos del 2010, una de cuyas recomendaciones más firmes consistía en que el ART se debía iniciar entre 2 y 8 semanas después de haber comenzado el tratamiento antituberculoso (con una calidad probatoria moderada). Algunos resultados científicos de aparición reciente respaldaban igualmente esta recomendación. Los investigadores consideraron 
que el protocolo del estudio en Viet Nam entraba en conflicto con las prácticas óptimas internacionales recomendadas e interrumpieron su realización en octubre del 2010. Se introdujeron modificaciones al protocolo, según las cuales el ART se comenzaría a las 2 semanas y se puso en práctica el estudio. En el presente artículo se analizan los aspectos éticos en torno a esta decisión y a la necesidad de modificar el protocolo del estudio.
Public Health Action (PHA) The voice for operational research. Published by The Union (www.theunion.org), PHA provides a platform to fulfil its mission, 'Health solutions for the poor'. PHA publishes high-quality scientific research that provides new knowledge to improve the accessibility, equity, quality and efficiency of health systems and services.
e-ISSN 2220-8372

Editor-in-Chief: Donald A Enarson, MD, Canada

Contact: pha@theunion.org

PHA website: http://www.theunion.org/index.php/en/journals/pha Article submission: http://mc.manuscriptcentral.com/pha 